14.03

\title{
Физические и физиологические проблемы медицинского мониторинга
}

\author{
() К.М. Лебединский, ${ }^{1,2}$ А.Н. Коваленко, ${ }^{3}$ И.С. Курапеев, ${ }^{1}$ А.Е. Карелов, ${ }^{1}$ А.И. Ленькин, ${ }^{1}$ В.В. Субботин, ${ }^{4}$ \\ П.А. Волков, ${ }^{5}$ Д.В. Мартынов ${ }^{6}$ \\ ${ }^{1}$ Северо-Западный государственный медицинский университет им. И.И. Мечникова Минздрава РФ, \\ 193015 Санкт-Петербург, Россия \\ ${ }^{2}$ Федеральный научно-клинический центр реаниматологии и реабилитологии, \\ 107031 Москва, Россия \\ ${ }^{3}$ Физико-технический институт им. А.Ф. Иофффе РАН, \\ 194021 Санкт-Петербург, Россия \\ ${ }^{4}$ Московский клинический научно-практический центр им. А.С. Логинова ДЗМ, \\ 111123 Москва, Россия \\ ${ }^{5}$ АО „Клиника К+31“, \\ 119415 Москва, Россия \\ ${ }^{6}$ Ростовский государственный медицинский университет Минздрава РФ, \\ 344022 Ростов-на-Дону, Россия \\ e-mail: mail@lebedinski.com
}

Поступило в Редакцию 3 февраля 2020 г.

В окончательной редакции 3 февраля 2020 г.

Принято к публикации 17 февраля 2020 г.

В обзоре в контексте исторического развития обсуждаются физиологические, инженерно-физические, эргономические, когнитивные и экономические аспекты медицинского мониторинга — одной из самых быстроразвивающихся и высокотехнологичных областей медицины и медицинской техники. Особое внимание уделено клиническим требованиям к мониторингу, мониторам и мониторируемым показателям, трудностям, спорным и проблемным аспектам мониторинга, в частности, интерпретации физиологических сигналов, влиянию мониторинга на исходы лечения пациентов, трудностям создания систем автоматического управления физиологическими функциями пациента на основе данных мониторинга и мониторингу интегральной оценки физиологического состояния организма человека, как необходимому дополнению, а иногда и более эффективной альтернативе традиционным „аналитическим“ видам мониторинга отдельных физиологических функций и параметров.

Ключевые слова: мониторинг медицинский, требования, классификация, проблемы, влияние на исходы; сигналы физиологические, интерпретация.

DOI: $10.21883 / J T F .2020 .09 .49670 .69-20$

\section{Введение. Назначение и задачи медицинского мониторинга}

Мониторингом (от англ. 〈to $\rangle$ monitor - напоминать, предупреждать, предостерегать) называют протяженное во времени наблюдение за каким-либо процессом или показателем в реальном масштабе времени [1]. Соблюдение этих двух временны́х условий, с одной стороны, дает возможность не просто оценить единичный отсчет, а отследить направление развития событий, с другой получаемая информация в каждый момент времени отражает не прошлое, а именно текущее состояние объекта наблюдения.

В английском языке, согласно американскому словарю Merriam-Webster (1993) [2], глагол to monitor употребляется с 1924 г. в значениях „наблюдать, отслеживать, проверять, обычно со специальной целью“. В русском первое употребление слова „монитор“ в значении „контрольный прибор“ датируется 21 октября 1957 г.: спустя две с половиной недели после запус- ка первого в мире искусственного спутника Земли газета „Правда“ писала о нейтронных мониторах [3]. Семейство слов с корнем „монитор“ происходит от индо-европейского корневого элемента men - думать, который породил множество производных, отражавших различные состояния и качества сознания и мышления (ср. менталитет, деменция) [4]. Для латинского глагола moneo, этимология которого проводится от существительного mens - сознание, рассудок, мысль, мнение „Латинско-русский словарь““ И.Х. Дворецкого (1976) [5] дает значения, часть из которых созвучна с современной ролью мониторинга: напоминать, обращать внимание; предостерегать, предупреждать; внушать, наставлять, указывать; предвещать, предсказывать. Для слова monitor там же приводятся значения: тот, кто напоминает; советник, консультант (в судебном процессе); тот, кто предостерегает, предупреждает; надзиратель, надсмотрщик.

Медицинский мониторинг столь же стар, как и медицина: следить за пациентом в ходе врачебного вме- 
шательства так же естественно, как его выполнять. Все развитие медицины тесно связано с совершенствованием методов и инструментальных средств диагностики и прогнозирования нарушений здоровья по физиологическим показателям функционирования организма. Они проявляются в разнообразных тепловых, механических, электрических, химических и других биологических сигналах, регистрируемых в системах медицинского мониторинга как в виде непосредственно измеряемых физических величин (температуры, давления, биоэлектрических потенциалов), так и величин, характеризующих взаимодействие организма с внешними физическими полями (величина ослабления прошедших через исследуемые ткани ультразвука, электромагнитных волн, оптического излучения). В зависимости от физической природы сигнала и необходимости его обработки данные могут восприниматься медицинским персоналом как посредством различных устройств (мониторов), так и непосредственно органами чувств зрением, слухом, осязанием. Правильная врачебная интерпретация измеряемых величин и данных визуализации медицинских изображений при полевых воздействиях на организм требует глубокого понимания как физиологических, так и физико-технических оснований, заложенных в методики получения и обработки сигналов используемыми инструментальными средствами. Физиологическая основа всех биологических сигналов в организме определяется процессами метаболизма как набора биохимических реакций обмена веществ органических и неорганических соединений для их использования в качестве источника энергии поддержания жизни при ферментной саморегуляции их кинетики со стороны нервной и эндокринной систем организма в зависимости от условий внешней среды и внутренних факторов. Протекание этих процессов подчиняется общим законам биохимической термодинамики и их конкретным физико-химическим выражениям, которые описывают превращения теплоты и работы в организме как открытой системе, обменивающейся веществом и энергией с окружающей средой. Это создает физикотехнические основания методик получения и обработки сигналов, а также разработки необходимых инструментальных средств. Отбор контролируемых показателей из всей их возможной совокупности осуществляется в зависимости от целей медицинских наблюдений от первичного осмотра, диспансерного обследования, специализированного контроля при лечении выявленных заболеваний, доврачебной и скорой помощи в условиях экстремальных ситуаций вплоть до непрерывного on-line мониторинга важнейших показателей жизнеспособности в критических состояниях с тяжелыми расстройствами жизненно важных систем организма. К ним, в первую очередь, относятся сердечно-сосудистая и дыхательная, а также регуляторная и выделительная системы, поражение которых при терминальном развитии с нарастающей гипоксией коры головного мозга с большой вероятностью может стать причиной летального исхода и требует экстренного восстановления с проведением реанимационных мероприятий в отделениях реанимации и интенсивной терапии.

Сегодня непрерывное присутствие во время анестезии обученного персонала является ключевым элементом любого стандарта мониторинга, начиная с первого Гарвардского [6]. Уже к середине XIX в. развитие клиники, прежде всего хирургии и неотложной медицины, породило потребность наблюдения в реальном времени объективных физиологических параметров пациента. Так, „первый анестезиолог“ John Snow (1813-1858) во время наркоза непрерывно пальпировал пульс, а выдающийся нейрохирург Harvey W. Cushing (1869-1939) ввел наркозную карту, отражавшую показатели внешнего дыхания и кровообращения [1]. Ненаписанная глава истории медицины - простые приспособления известных предметов и приборов, обеспечивавшие мониторинг сложных физиологических функций, от ватных „усов“ на верхней губе, позволявших наблюдать дыхание пациента, до стетоскопа, соединенного с зондом в пищеводе, чтобы без помех слышать мелодию сердца.

Поскольку ведущей проблематикой медицины критических состояний является гипоксия, особенный интерес представляет развитие мониторинга цепи транспорта кислорода. Его отправной точкой стало визуальное наблюдение цианоза: при концентрации деоксигенированного гемоглобина $\mathrm{Hb}$ более $50 \mathrm{~g} \cdot 1^{-1}$, метгемоглобина MetHb более $15 \mathrm{~g} \cdot 1^{-1}$ и сульфгемоглобина $\mathrm{HbSO}_{4}$ более $5 \mathrm{~g} \cdot 1^{-1}$ становится видимой синеватая (у африканцев серая) окраска кожи и слизистых [7], из чего вытекает возможность применения методов спектроскопии для объективного контроля насыщения гемоглобина кислородом и детекции гемоглобинопатий. Уже в 1933 г. Karl Matthes (1905-1962) в Германии создал первый чрезкожный оптический оксиметр, работавший, подобно современным пульсоксиметрам, в красной и инфракрасной областях спектра [8]. В 1942 г. американский физиолог Glen A. Millikan (1906-1947), сын известного физика Robert A. Millikan (1868-1953), разработал для британских Королевских ВBC серийный двухчастотный гемоксиметр, датчик которого был снабжен красным и зеленым светофильтрами и крепился пилоту на мочку уха. О приближении критической высотной гипоксемии прибор предупреждал звуковым сигналом, а бортовая кислородная система фирмы Bendix автоматически включала подачу $\mathrm{O}_{2}$ под лицевую маску [9]. В СССР аналогичный оксиметр был создан в 1944 г. физиологом Е.М. Крепсом (1899-1985) и инженерами М.С. Шипаловым, Е.А. Болотинским и А.Г. Крейцером, и серийно выпускался ленинградским заводом „Красногвардеец“ [10]. В 1951 г. R.C. Steven, H.M. Slater и A.L. Johnson применили оксиметр Милликена в операционной [11], отечественные серийные оксигемографы О26, О36 и О57 применялись и советскими анестезиологами [12] (рис. 1). Крупнейший прорыв совершил в 1975 г. японский исследователь Такуо Аояги, изучавший спектрографические кривые вымывания 

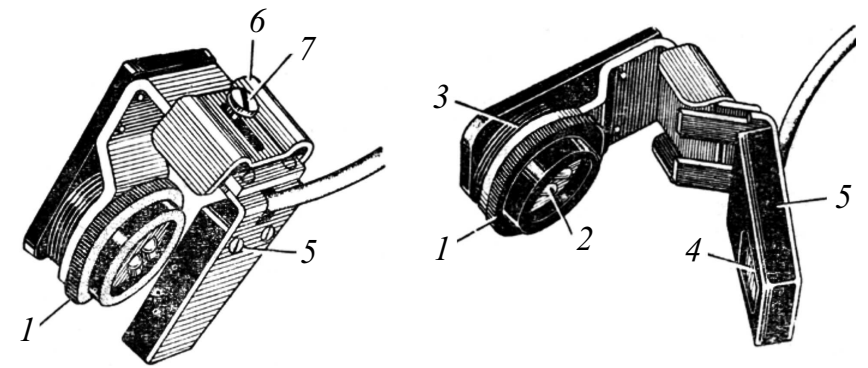

Pис. 1. Датчик советского серийного оксигемографа О36М („Красногвардеец“, Ленинград) в закрытом (слева) и открытом (справа) состоянии [10]; 1 - тубус, 2 - фотопреобразователи, 3 - обойма, 4 - окно корпуса, 5 - фотоэлементный корпус, 6 - скоба, 7 - винт.

красителя из крови. Пульсации артериального потока были артефактом, с которым он вначале боролся, а затем стал использовать в качестве полезного сигнала: в норме поток пульсирует только в артериолах, а потому спектрография пульсирующей компоненты потока наиболее близко отражает состав артериальной крови. В конце 1970-х г. Scott Wilbur из компании Вiox изобрел компактный датчик на фотодиодах - двух излучающих и приемном, отказавшись от фиброоптических линий пульсоксиметра Аояги, а внедрение в начале 1980-х г. фирмами Biox и Nellcor микропроцессорной обработки сигнала окончательно сделало пульсоксиметр тем повседневно и повсеместно необходимым монитором, каким он является сегодня [8]. В XXIв. распространение получили чрезкожная околоинфракрасная тканевая (в том числе церебральная) оксиметрия и многочастотная кооксиметрия (технология Rainbow, Massimo, США), позволяющая оценивать концентрацию общего гемоглобина крови и его фракций $[13,14]$, однако нуждающаяся в повышении точности и помехоустойчивости [15].

\section{1. Принципы классификации и требования к медицинскому мониторингу}

Мониторировать можно любой протяженный во времени процесс. Но необходимость в мониторинге появляется, когда запаздывание информации ведет к значимым потерям данных и утрате эффективности вмешательства. Потребность в мониторинге тем выше, чем больше динамизм процесса, чем более серьезными последствиями чревато „отставание от событий“ и чем более действенны возможности влияния на их ход [1].

Рассматривая мониторинг как инструмент безопасности пациента в руках врача, обратимся к понятию критического инцидента (КИ), введенному в анестезиологию Jeffry Cooper в 1974г. Под КИ понимают „... .шшибку человека либо поломку оборудования, которые (не будучи вовремя распознаны и устранены) могли бы привести или привели к неблагоприятным последствиям $\langle\ldots\rangle$ вплоть до летального исхода“" $[16]$. Не всякий КИ является осложнением; цепь развития осложнения через посредство КИ выглядит так: инцидент (событие с малым риском причинения вреда), критический инцидент, обратимое нежелательное явление, осложнение, и, наконец, необратимое осложнение вплоть до летального исхода. Чем меньше частота КИ, тем совершеннее система безопасности.

Мониторинг в этой концепции играет ведущую роль как инструмент выявления и регистрации КИ. Однако только выявить и зарегистрировать КИ недостаточно для обеспечения безопасности пациента, так как „не будучи вовремя устранены“, КИ приводят к развитию осложнений. На первый план выходит проблема, о которой подробнее будет сказано ниже: принятие решений персоналом, так как сам по себе монитор не лечит!

Основным источником КИ и осложнений является ошибка человека; по мнению некоторых авторов, ее доля может достигать 83\% [17]. А поскольку людям свойственно недооценивать или скрывать свои ошибки, мониторинг просто необходим. Это подтверждает исследование А.К. Јha с соавторами (1998 г.), в котором врачи заявили лишь о 4\% нежелательных событий, связанных с лекарствами, из 45\%, выявленных мониторами [18].

Целями мониторинга являются повышение безопасности и улучшение качества управления процессом [1], достигаемые за счет:

$a$ - упреждающей коррекции негативных тенденций (устранения КИ);

$\sigma$ - прогнозирования нештатных, в том числе опасных ситуаций;

в - незамедлительного информирования о развитии таких ситуаций;

2 - дифференцирования патогенетических механизмов их развития;

$\partial-$ обеспечения обратной связи в процессе управления;

$x$ - возможности безопасного применения мощных средств управления [19];

з - документирования массивов данных для решения различных задач.

Отметим, что в целом ряде случаев перечисленные задачи нелегко решить совместно. Например, пульсоксиметрия и капнография - мониторинг концентрации $\mathrm{CO}_{2}$ в газовой смеси на вдохе и выдохе - великолепно исполняют роль универсального тревожного звонка (по п.в), тогда как для дифференцировки различных механизмов повреждения дыхательной цепи (по п. г) эти методы дают не так много информации.

Мониторинг должен удовлетворять целому ряду клинических требований, наиболее универсальные из которых можно суммировать следующим образом [1]:

1) обоснованность - наличие достаточных оснований для того, чтобы на нынешнем уровне развития естествознания и медицины, в частности, считать данный вид мониторинга показанным в данной конкретной ситуации данному конкретному пациенту; 
2) целенаправленность - нацеленность, во-первых, на решение конкретных клинических задач, и, прежде всего, - задачи обеспечения безопасности больного, во-вторых, на получение информации, наиболее важной именно в данном случае;

3) достоверность и точность - соответствие получаемой информации действительности с максимально возможным приближением отсчетов к истинным значениям мониторируемых параметров;

4) непрерывность - исключение перерывов в отслеживании ситуации, способных привести к внезапному для врача возникновению угрожающей ситуации или к непониманию причин событий из-за незнания последовательности их развития;

5) активность - инициативное использование для решения задач мониторинга всех возможностей, в том числе и необычных, диктуемых условиями обстановки;

6) минимальная инвазивность - сведение медицинских и юридических рисков, связанных с самой процедурой мониторинга, к минимуму, необходимому и достаточному для решения его клинических задач;

7) клинико-экономическая эффективность - финансовая доступность необходимого оборудования и расходных материалов лечебному учреждению и отсутствие более дешевых альтернатив, дающих сходный клинический результат.

Показательно, что перечисленное в значительной меpe (пп. 2-5) буквально совпадает с требованиями к такому виду боевого обеспечения войск, каким является разведка [20], представляющая собой, прежде всего, мониторинг ситуации.

Что именно следует мониторировать в клинике? J.B. Hall (2005) [21] формулирует следующие требования, которым должен удовлетворять физиологический параметр, чтобы претендовать на роль объекта мониторинга в медицине критических состояний: изменения данного показателя в течение заболевания должны иметь логичные патофизиологические обоснования; показатель должен быть доступным для надежной и достоверной оценки в обычных условиях; показатель должен предоставлять информацию, недоступную при использовании более простых методов мониторинга, и должно существовать лечебное вмешательство, способное воздействовать на него; управление лечебными воздействиями на основании данного показателя должно оказывать положительное влияние на исходы лечения.

Сегодня стало модно, говоря о тех или иных средствах, формулировать концепцию „идеального препарата“, „идеального метода“, „идеального прибора“ и т. п. „Идеальный монитор“, согласно G. Satkurunath, A. Rhodes и M. Cecconi (2009) [22], должен быть: способным давать точные и воспроизводимые данные; полезным для клинициста; улучшающим исходы у пациентов; дешевым; простым в применении и интерпретации данных; не создающим для пациента дополнительных рисков; легким в транспортировке; нетребовательным в обслуживании; свободным от артефактов; снабженным тревогами по параметрам, требующим немедленного вмешательства.

Не сомневаясь в ценности всего перечисленного, подчеркнем важное ограничение. Любой монитор, даже самый совершенный, сам по себе не может влиять на исходы лечения, поскольку воздействует на больного не прямо, а посредством персонала, принимающего решение и исполняющего его. Очевидное исключение, пожалуй - осложнения мониторинга как такового. Особенно ярко эта коллизия влияния мониторинга на исход проявилась в дискуссиях, посвященных катетеризации легочной артерии. Правомерная постановка задачи выглядит примерно так: эффективный монитор должен предоставлять персоналу информацию, способную, при условии правильной и единообразной ее интерпретации, обеспечить своевременное принятие тактических решений и мер, положительно влияющих на исходы лечения [1].

Медицинский мониторинг классифицируют по объекту (физиологической функции, физическому или химическому параметру - мониторинг дыхания, гемодинамики, нейромышечной проводимости, метаболизма, сатурации гемоглобина кислородом, температуры тела и др.), по физической природе физиологического сигнала (оптический, механический, термический, электрофизиологический и др.) и его характеру (спонтанный или вызванный: сравним измерение температуры тела с анализом термодилюционной кривой, записанной с катетера в легочной артерии; электрокардиографию с импедансной кардиографией; нативную электроэнцефалограмму и соматосенсорные вызванные потенциалы и т.Д.), по особенностям его обработки (органолептический, компьютерный, запись трендов и др.), наконец, по степени инвазивности [1]. Одна из тенденций сегодня - переход от инвазивных процедур (например, катетеризация легочной артерии) к мало- (чрезпищеводная эхокардиография) или неинвазивным аналогам (фотоплетизмографический расчет сердечного выброса).

Отметим еще один признак, по которому можно классифицировать технологии мониторинга с когнитивной точки зрения: существуют мониторы - более или менее универсальные сигнализаторы тревоги (таковыми являются, например, пульсоксиметр, капнограф, детектор пузырьков газа в контуре искусственного кровообращения) и мониторы - инструменты измерения (например, катетер Свана-Ганца в легочной артерии или акцелерометрический монитор нейромышечного проведения). С точки зрения влияния на исходы лечения намного больше вопросов вызывает второй тип мониторов.

В заключение сказанного подчеркнем роль мониторинга как средства документирования событий. Во многих случаях только данные объективной регистрации позволяют вынести определенное суждение о том, что и в какой последовательности произошло во время анестезии или реанимационных мероприятий. К сожалению, подобная информация не всегда свидетельствует в пользу врача, в том числе при администра- 


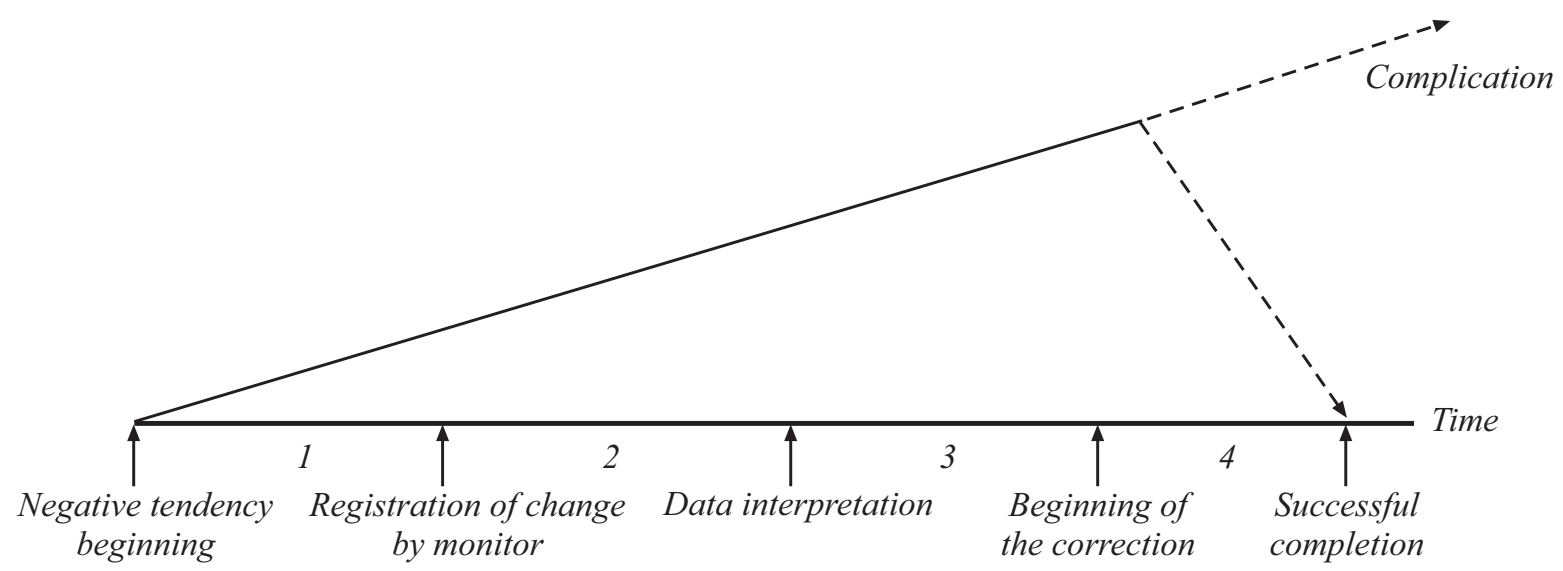

Рис. 2. Процесс коррекции развития негативной тенденции: 1 - период от начала развития тенденции до регистрации монитором изменения параметра, 2 - период от обнаружения оператором изменения параметра до понимания причины, 3 - период принятия решения о необходимых действиях, 4 - период от начала коррекции до успешного разрешения возникшей проблемы [28].

тивных и уголовных разборах [23]. Однако нет сомнений в том, что в ближайшем будущем концепция „черного ящика“, фиксирующего динамические ряды всех мониторируемых показателей и, вероятно, переговоры персонала и пациента будет перенесена в медицину. Сегодня в европейских отделениях неотложной помощи установлены камеры видеонаблюдения, записи которых сохраняют как минимум в течение ближайших суток: в случае конфликтов, нередких в драматических условиях экстренной медицины, видеопротокол всегда на стороне добросовестных профессионалов.

\section{2. Проблемы и трудности мониторинга}

На первый взгляд, основной проблемой аппаратного мониторинга являются самые разнообразные артефакты и помехи, нередко затрудняющие получение полезной информации, а подчас и делающие мониторинг вовсе невозможным. Хрестоматийный пример - артефакты ЭКГ от работы электрохирургического оборудования наглядно показывает ряд общих закономерностей. Прежде всего, артефактам наиболее подвержены те методики мониторинга, которые предполагают работу с физиологическими сигналами низкой энергетической насыщенности (биопотенциалы: ЭКГ, ЭЭГ и т.д.), в то время как более энергоемкие „отраженные“ сигналы оказываются значительно более защищенными (пульсоксиметрия, акцелеромиография, импедансная кардиография и т.д.). Вовторых, количество и характер артефактов критическим образом зависят от качества мониторного оборудования, в частности, использованных в нем аппаратных и программных средств фильтрации сигнала. В-третьих, наиболее уязвимой в отношении ошибок оказывается автоматическая интерпретация сигнала; поэтому общим правилом является отключение этой опции, как только сигнал оказывается зашумленным.
Проблема артефактов - одна из главных причин того, что в рутинном мониторинге пока не нашла достойного места такая ценная с научной и практической точек зрения технология, как регистрация вызванных потенциалов (ВП). Несмотря на то, что вызванная активность выгодно отличается от нативной ЭЭГ в плане информативности, необходимость выделения ВП методом усреднения при многократном повторении стимулирующего импульса и ответа ЦНС приводит иногда к значимой задержке получения результата и „размыванию“ точки отсчета во времени. Низкая амплитуда вызванного ответа (иногда в десятки раз (!) меньше амплитуды нативной ЭЭГ - в данном случае ответный сигнал слабее спонтанного) требует до нескольких сотен повторений для получения интерпретируемого ВП. Опорным моментом для такой суммации является момент подачи стимулов. В результате такого накопления сигнал ВП, закономерно связанный со стимулом, растет значительно быстрее, чем шум спонтанной ритмики, не связанный со стимулом [24]. Значимая задержка в получении результата, а также особые условия записи и необходимость использования мощных фильтров сигнала ограничивают широкое применение этой методики в клинической практике. Из множества технологий в периоперационной практике ограниченно используются в наши дни, пожалуй, только две: мониторинг ССВП при операциях на спинном мозге и при каротидных эндартерэктомиях, и мониторинг слуховых вызванных потенциалов средней латентности (MLAEP) для оценки глубины гипнотического компонента общей анестезии (например, монитор AepEX plus - Audiomex, Великобритания) [25]. Отметим, последняя технология единственная, позволяющая оценивать глубину сна пациента при анестезии препаратами, вызывающими так называемую „диссоциативную анестезию“ с атипичным паттерном нативной ЭЭГ (кетамин) [26].

И все же необходимо подчеркнуть, что главной проблемой мониторинга являются не артефакты и ошибки. 
Зарубежные коллеги, давно и постоянно работающие с современными мониторами, единодушно называют основной трудностью интерпретацию данных, которые монитор предоставляет персоналу [27]. Это отлично проиллюстрировано (рис. 2) в обзоре L.A. Eidelman и соавторов „Философия мониторинга“ [28]. Обратим внимание, что проблемы, связанные с аппаратурой, занимают только один первый период в цепи развития и пресечения негативной тенденции. Все остальное влияние человеческого фактора.

Трудности интерпретации данных мониторинга могут быть результатом недостаточно глубокого понимания врачом или сестрой физиологических и/или физических принципов работы монитора. Ясно, что первое и необходимое условие работы с любым монитором - не приблизительное, „ориентировочное“, а абсолютно точное, буквальное понимание того, что именно (на первичном физическом или химическом уровне!) он показывает. Как показывает преподавательский опыт, проблема далека от решения: на вопрос „Сатурацию какой именно крови показывает пульсоксиметр, или что именно обозначает аббревиатура $\mathrm{SpO}_{2}$ ? “ на протяжении 18 лет не ответил точно ни один из наших врачей-слушателей. Более того, в современной зарубежной литературе встречаются выражения вроде „Пульсоксиметрическое измерение артериальной сатурации $\mathrm{SpO}_{2}$ “ [14]. Между тем без точного ответа на этот вопрос невозможно понять, почему при инфузии нитроглицерина монитор может показать $88 \%$, а анализ газов артериальной крови даст 99\%!

Важным частным случаем ошибочной интерпретации данных мониторинга является так называемый „гипноз монитора“. „Never treat the Monitor!“ (англ. Никогда не лечи монитор!) - учат молодых врачей зарубежные коллеги, а между тем фиксация внимания на показаниях только одного прибора с полным отключением оператора от контекста событий и других приборов частая проблема и вне медицины. Как следует из официального отчета о расследовании катастрофы самолета Президента Польши в Смоленске 10 апреля 2010 г. [29], одной из причин ошибочных действий пилота на глиссаде была фокусировка внимания на громком отсчете штурманом показаний бортового радиовысотомера PB-5: пренебрегая показаниями других приборов, пилот оказался полностью дезориентирован в пространственном положении самолета относительно земли. Аналогичной была непосредственная причина столкновения парохода „Адмирал Нахимов“ с сухогрузом „Петр Васев“ на выходе из Цемесской бухты 31 августа 1986 г.: капитан сухогруза вел судно „по локатору“, игнорируя визуальное сближение с пароходом [30].

Чем совершеннее мониторы, тем выше вероятность ошибки из-за неаккуратности обращения с ними, невыполнения технических регламентов и инструкций, подчас самых банальных. Неважно, что многие из этих правил вообще не имеют прямого отношения к специфическим медицинским вопросам: даже чужая фамилия, вес или рост другого пациента в памяти монитора могут привести к ошибкам интерпретации состояния и, как результат, к неправильной тактике. Не случайно еще в 1949 г. профессиональная дисциплина заняла почетное шестое место среди десяти самых острых проблем здравоохранения США (цит. по [31]). Так происходит не только в медицине: вторая по тяжести после Чернобыля авария на АЭС Three Mile Island (Пенсильвания, США, март 1979 г.) произошла, в частности, из-за того, что бленкеры отказа конденсатных насосов на пульте управления были завешены табличкой „Осторожно, окрашеHo! " [32].

Еще одна проблема называется в инженерной психологии информационной перегрузкой оператора [33]. Когда в операционной сосредоточены экраны 4-5 разных мониторов, одному врачу-анестезиологу трудно и вести анестезию, и контролировать все показатели. Мы в свое время решили проблему просто - работали бригадой из 2-3 человек, обязательным членом которой был врач, исполнявший обязанности клинического физиолога. Авиация, столкнувшаяся с подобной проблемой гораздо раньше анестезиологии, успела отработать несколько путей решения. Это, в частности, так называемый директорный режим пилотирования, когда необходимая пилоту информация выдается в виде прямых указаний типа „вправо-влево“ и „вверх-вниз“, т.е. не требует анализа. В подобном режиме, например, самолет пилотируется на посадочной глиссаде „по стрелкам“ командно-пилотажного прибора.

Другой подход, используемый создателями авиатехники - переход от бесчисленных стрелочных приборов к так называемым интегральным индикаторам на ЖКэкранах, представляющим всю необходимую экипажу информацию в виде цветной наглядной блок-схемы. Приборные доски самолетов в последние два-три десятилетия изменились до неузнаваемости, что заметно повысило эффективность работы экипажа и снизило его утомляемость (рис. 3). Вероятно, подобная „эргономическая революция“ ожидает в ближайшем будущем и медицинскую технику; такие образцы уже есть - например, швейцарский производитель оборудования для респираторной поддержки Hamilton Medical AG внедрил для мониторинга механики внешнего дыхания пациента весьма наглядный экранный симулятор в виде простой блок-схемы (его можно посмотреть в действии [34]).

Другим вариантом снижения информационной перегрузки оператора могут быть системы поддержки принятия решений (англ. Clinical Decision Support, CDS) на основе компьютерного анализа входящей информации, либо полностью автоматизированные системы с обратной связью, которым ниже посвящен разд. 3.5.

Необходимо упомянуть еще об одном устройстве, которое может быть применено в операционной - это так называемые головные дисплеи (англ. Head-mounted displays, HMDs), при помощи которых анестезиолог может контролировать мониторируемые параметры, не отвлекаясь от происходящих в операционной событий. 


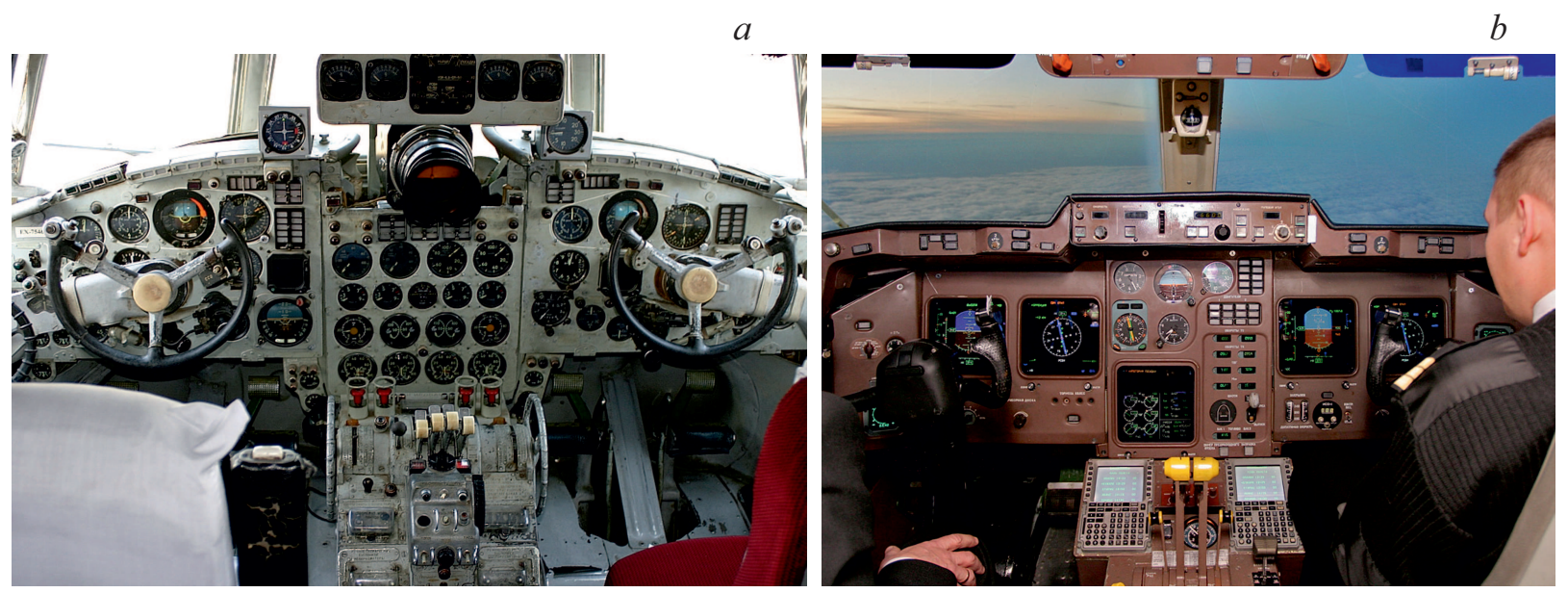

Рис. 3. Компоновка главных приборных панелей турбовинтовых пассажирских самолетов ОКБ им. С.В. Ильюшина: $a-$ Ил-18, 1957 г. (фото S. Bailleul, 2003), b - Ил-114, 1990 г. (фото Ф. Борисова, 2006) [1].

Они прошли путь от неудачных попыток применения изза плохого разрешения и коротких шлейфов, соединяющих дисплеи с компьютером в 1995 г. [35], до восторженных отзывов анестезиологов в 2019 г.: „Анестезиологи, которые участвовали в исследовании, выразили энтузиазм по поводу наблюдения за пациентами при помощи головных дисплеев и высказали желание использовать их в дальнейшем“ [36]. Возможно, головные дисплеи получат свое дальнейшее развитие в приспособлениях, прототипом которых являются очки „Google Glass“ [37].

\section{3. Физиологические и физические парадоксы медицинского мониторинга}

Существуют общие методологические проблемы мониторинга как специфического метода клинического наблюдения в реальном времени, осуществляемого в большинстве случаев у нестабильных пациентов. В числе таких проблем (назовем их парадоксами современного мониторинга) можно выделить следующие.

\section{1. Метод или нужен, или он работает}

Давно известно: любой монитор работает наиболее устойчиво, дает наиболее точные результаты (англ. accuracy) с наиболее высокой воспроизводимостью (англ. precision) у...здоровых людей! У больных же, т.е. тогда, когда результат, собственно, и интересует врача, действует огромное количество самых разнообразных помех [1].

В последние годы за рубежом стало модным „развенчивать“ мониторные параметры на основании того, что во многих конкретных клинических ситуациях они действительно не отражают состояния того физиологического показателя или функции, которые изначально призваны характеризовать. Так, центральное венозное
Известные клинические факты о достоверности показателей мониторинга кровообращения [38]

1 ЦВД не коррелирует с конечно-диастолическим давлением в правом желудочке (Nelson L.D., 1997)

2 ДЗЛА ненадежно коррелирует с конечно-диастолическими объемами правого или левого желудочков (Nelson L.D., 1997)

3 ЦВД и ДЗЛА не позволяют прогнозировать динамику сердечного выброса в ответ на инфузионную нагрузку объемом (Diebel L.N., Wilson R.F., Tagett M.G., Kline R.A., 1992; Pinsky M.R., 2002; Reuter D.A., Felbinger T.W., Schmidt C. et al., 2002)

4 Оценка сердечного выброса по клиническим признакам невозможна (Eisenberg P.R., Jaffe A.S., Schuster D.P., 1984)

5 Нормальные величины среднего АД не означают достаточного уровня сердечного выброса (Eisenberg P.R., Jaffe A.S., Schuster D.P., 1984)

6 Нормальные расчетные значения транспорта кислорода не означают адекватной перфузии органов (Schlichtig R., Kramer D.J., Pinsky M.R., 1991)

7 Нормальное содержание кислорода в смешанной венозной крови не означает адекватной перфузии органов (Boldt J., 2002)

8 Изменение потребления кислорода в результате изменения его доставки само по себе не означает наличия кислородной задолженности (Bellomo R., Pinsky M.R., 1996)

9 ДЗЛА не соответствует давлению в легочных капиллярах в момент заклинивания (Pinsky M.R., 2003)

давление (ЦВД), а затем и давление заклинивания легочной артерии (ДЗЛА) оказались не слишком надежными индикаторами преднагрузки сердца, нормальное артериальное давление (АД) далеко не всегда гарантирует достаточную перфузию тканей, и даже высокий 
сердечный выброс может сопутствовать тяжелой системной гипоперфузии . . . Приведем таблицу, заимствованную из обзора R. Bellomo и S. Uchino (2003) [38], изучая которую, надо ясно понимать: хотя все или почти все изложенное там - чистая правда, последствия ортодоксального приложения выводов к повседневной практике могут быть самыми разрушительными. Недоверие сразу ко всем навигационным приборам (хотя каждый из них в отдельности, как известно, ошибается в тех или иных обстоятельствах!) неизбежно приводит корабль к гибели. Правильный вывод отсюда только один - во всех ситуациях надо стремиться использовать максимум доступной информации, чтобы не оказаться заложником ограничений метода-монополиста. С другой стороны, расхождение данных, полученных разными методами мониторинга одного показателя или процесса, всегда дает больше информации, чем их совпадение: надо только понять его причины.

\section{2. Парадокс размывания временно́го пятна}

Этот парадокс мониторинга можно назвать феноменом ускользания смысла. Известно, что любой единичный отсчет несет в себе ту или иную ошибку неважно, систематическую или случайную; уменьшить влияние ошибок позволяют статистические методы, основанные на наборе и обработке более или менее значительных массивов таких дискретных отсчетов. Получается, что ошибка уменьшается по мере того, как оценка текущего состояния, нередко меняющегося весьма динамично, все больше „размазывается“ во времени. Врач, таким образом, оказывается перед классическим выбором - знать почти все, но ни о чем, или не знать ничего, но зато обо всем.

\section{3. Недоступность главного целевого показателя мониторируемой функции}

В отличие от экспериментальной физиологии клинике пока недоступна количественная оценка многих параметров, например, главного целевого показателя кровообращения - тканевого кровотока $\left(\right.$ в $\left.\mathrm{ml} \cdot 100\left((\text { tissue } \mathrm{g})^{-1} \cdot \mathrm{min}^{-1}\right)\right)$. В итоге мы оцениваем работу системы и вмешиваемся в нее (нередко успешно!), контролируя ее эффективность лишь по косвенной информации - например, „брутто-кровотоку“, т.е. минутному объему кровообращения.

\section{4. Может ли мониторинг влиять на исходы?}

Как упоминалось выше, положительное влияние на исходы лечения пациентов выдвигается в качестве важного клинического требования к мониторингу [21,22]. В то же время, очевидно, что, будучи лишь источником информации, ни один монитор не в состоянии оказать на исход влияние, не опосредованное бдительностью, решениями и действиями медицинского персонала. Японская атака на Пирл-Харбор 7 декабря 1941 г. убедительно доказала, что находящаяся на боевом дежурстве исправная радиолокационная станция сама по себе не повышает эффективности ПВО. Неудивительно в этом свете, что использование или неиспользование пульсоксиметра у 20802 хирургических пациентов не влияло на частоту периоперационных осложнений и госпитальной летальности [39]. Только частота „анестезиологических“ смертей, согласно данным Британского конфиденциального опросника NCEPOD, почему-то снизилась с 1 случая на 10 тыс. анестезий в 1982 г. до 1 случая на 200 тыс. анестезий в 1987г. [40], что удивительным образом совпало с массовым внедрением в Великобритании пульсоксиметров . . .

Логику, которая непротиворечиво согласовывает между собой подлинность этих фактов, помогает понять динамика взглядов врачебного сообщества на катетеризацию легочной артерии с помощью баллонного катетера Свана-Ганца с 1970-х по 2000-е [41]. В момент внедрения в клинику в начале семидесятых этот катетер представлял собой единственный клинически доступный инструмент, позволявший в реальном времени и с хорошей дискретностью получать важнейшие данные о производительности и преднагрузке сердца, системном потреблении кислорода, а впоследствии - и о функции правого сердца, внутрисердечной ЭКГ, мониторировать сердечный выброс в непрерывном режиме и т. д. Усилиями энтузиастов метода был впервые накоплен огромный массив цифровых данных о гемодинамике во время анестезии и интенсивной терапии, а к середине 1990х в США в год выполнялось свыше миллиона этих высокоинвазивных процедур [42]: по существу, почти каждый пациент, попадавший в американское отделение интенсивной терапии, получал катетер Свана-Ганца! И в то же самое время появлялось все больше публикаций о том, что использование катетера в легочной артерии у самых различных категорий пациентов не улучшает исходы, а только способствует осложнениям катетеризации как таковой и росту расходов [43].

Наконец, в сентябре 1996 г. в „Журнале Американской медицинской ассоциации“ (ЈАМА) появилась эпохальная статья Alfred Connors и соавт. [44], которые на основе анализа результатов лечения 5735 пациентов в пяти университетских клиниках США показали, что использование катетера Свана-Ганца не только увеличивает койко-день с 13 до 14.8, а стоимость лечения с 35.700 до 49.300 USD (цифра отражала, конечно, не цену катетера, а стоимость койко-дня в американском ОРИТ - отделении реанимации и интенсивной терапии!), но и на $24 \%$ снижает месячную выживаемость больных. Сенсационная публикация сопровождалась редакционной статьей под характерным названием: „Настало время извлечь катетер из легочной артерии?“ [45]. И хотя дизайн работы немедленно вызвал справедливые нарекания (в частности, в исследование включали заведомо инкурабельных пациентов!), результат не замедлил сказаться. В США зазвучали призывы к национальному 
мораторию на эту методику [42], немедленно вырос интерес к неинвазивным альтернативам - импедансометрическим и сонографическим методам, а в пользу отказа от инвазивного мониторинга стал высказываться даже один из первых адептов катетера Свана-Ганца W.C. Shoemaker [46].

В 1996-2006 многочисленные исследования, охватившие тысячи больных, показали отсутствие положительного эффекта и/или повышение риска осложнений и смерти в связи с катетеризацией легочной артерии. Подобные результаты были получены у пациентов, подвергающихся реваскуляризации миокарда [47], в том числе отдельно — на работающем сердце [48], в большой плановой хирургии $[49,50]$, у пациентов отделений реанимации общего профиля [51-53], а также при декомпенсированной сердечной недостаточности [54], тяжелом сепсисе [55] и остром респираторном дистресссиндроме [56-58].

Анализируя эти и другие данные, A.B. Leibowitz и J.M. Oropello (2007) [59] назвали несколько причин негативных оценок. Прежде всего, это выбор пациентов, многие из которых оказались или слишком легкими, или слишком тяжелыми для того, чтобы использование данных мониторинга могло улучшить исходы. Вовторых, уязвимость ДЗЛА как показателя волемии. Наконец, многочисленные методические ошибки в оценке и трактовке параметров мониторинга.

Взвешенную позицию высказали M.R. Pinsky и J.-L. Vincent в статье „Давайте использовать катетер в легочной артерии правильно и только тогда, когда он нам нужен“ (2005) [60]. Осудив „неразборчивый“ (англ. indiscriminate) отказ от использования катетера Свана-Ганца, авторы обратили внимание на целый ряд логических ошибок в аргументации противников метода, как такового. Риски, связанные с катетеризацией, за исключением нарушений ритма, в основном обусловлены центральным венозным доступом, - от которого, впрочем, никто отказываться не собирался; „специфичные“ для катетера Свана-Ганца разрывы легочной артерии и образование узла представляют очень редкие явления. Измерение смешанной венозной сатурации и давлений в легочной артерии остаются до сего дня незаменимыми возможностями, между тем как ошибки в измерении и трактовке ДЗЛА требуют не отказа от его измерения, а систематичного образования. Увеличение стоимости лечения за счет применения катетера примерно на 100-300 USD пренебрежимо мало́ в сравнении со стоимостью интенсивной терапии в целом (средний койко-день ОРИТ в США стоил в начале XXI в. около 12.000 USD [61]). Наконец — и это главное! ни один метод мониторинга сам по себе не влияет и не может влиять на результаты лечения больных. Данные, получаемые с помощью катетера, могут рассматриваться только в контексте четкого алгоритма (протокола) терапии, и только сравнение результатов следования такому протоколу с протоколом, не предусматривающим катетеризации, может быть аргументом за или против нее.
Таким образом, сложный вопрос с неочевидным ответом можно логически разложить на два последовательных вопроса, ответы на каждый из которых более очевидны:

1. Дает ли данный монитор врачу дополнительную объективную информацию о пациенте, которую нельзя получить иными способами?

2. Влияет ли эта информация, при условии ее обоснованного и единообразного влияния на тактику врача, на судьбу пациента?

Сегодняшний консенсус по гемодинамическому мониторингу при шоке (2014), не рекомендуя рутинное применение катетера Свана-Ганца у всех пациентов в шоке, в то же время отводит ему роль „арбитра“ при тяжелом шоке и в сложных гемодинамических ситуациях, когда шок устойчив к терапии, имеется дисфункция правого желудочка сердца или острый респираторный дистресссиндром [62].

\section{5. Почему до сих пор не замкнулась петля обратной связи?}

Еще один физико-технический парадокс состоит в том, что ни совершенствование аппаратных средств съема, передачи, цифровой обработки (фильтрации) и представления (интерпретации) физиологических сигналов, ни развитие устройств управления физиологическими функциями или их прямого протезирования пока не привели к массовому внедрению систем автоматического управления (САУ) на основе ,замкнутой петли“ (англ. closed loop) обратной связи по физиологическим параметрам. Основной барьер здесь - психологический: принято считать, что изменить режим искусственной вентиляции легких или скорость введения препарата может только врач, доверять это автомату нельзя. В нашей стране эта максима сегодня еще окрашивается в специфический криминально-сутяжный оттенок [23] вопросом „А кто будет отвечать в случае сбоя автомата?“. В то же время уже лет сорок никого не удивляет, что жизни 200-300 авиапассажиров можно доверить автопилоту, включая этапы взлета и посадки.

Надо сказать, что первая волна попыток внедрения САУ на основе физиологического мониторинга в анестезиологию и интенсивную терапию прошла еще в 1950-1960-е Так, первые автоматические респираторы - американский „Autoanestheton“ и советский POA-2 - автоматически подстраивали частоту дыхания для выдерживания заданного врачом значения конечноэкспираторного $\mathrm{PCO}_{2}$. Как стало ясно вскоре, эти первые опыты оказались в значительной мере, говоря юридическим языком, „попытками с негодными средствами“; замечательная панорама попыток внедрения САУ в анестезиологию дается в обзоре литературы докторской диссертации В.М. Магилевца [63].

Существуют и физико-технические проблемы создания таких САУ. Например, подбор коэффициентов пропорционально-интегрально-дифференциального 
(ПИД-) регулятора [64] требует знания собственной частоты колебаний и постоянной времени $\tau$ объекта управления. Между тем даже просто объяснить врачу, что такое „собственная частота малого круга кровообращения“ или „ $\tau$ среднего артериального давления при введении болюса нитроглицерина“, оказывается трудной когнитивной проблемой.

В то же время разработка систем с замкнутой петлей обратной связи, когда врач только задает целевые показатели, которые необходимо поддерживать на заданном уровне, актуальна и востребована современной клиникой. Преимущества таких систем (англ. Closed loop anesthesia delivery system - CLADS) очевидны, например в анестезиологии, в частности, потому, что такие системы:

1 - анализируют параметры анестезии более часто и тщательно;

2 - уменьшает вариативность анестезии, снижая вероятность грубых ошибок и КИ [65];

3 - экономят время анестезиолога, позволяя ему фокусироваться на важных клинических задачах и принимать верные решения;

4 - значительно уменьшают вероятность гипотензии при индукции общей анестезии;

5 - в целом обеспечивают более стабильную гемодинамику во время операции;

6 - создают лучший профиль пробуждения $[66,67]$.

Все вышеперечисленное позволит сделать работу врача анестезиолога-реаниматолога более приятной и безопасной, освободит его от рутины, упростит документацию и позволит ему сосредоточиться на пациенте и решении более важных клинических задач, особенно в сложной или критической ситуации [68].

В феврале 2020 г. ведущий мировой журнал „Anesthesiology“ опубликовал результаты исследования, проведенного в 2017-2019 в брюссельском госпитале Erasm [69]. Группы из 43 и 44 пациентов, в которых контроль анестезии, анальгезии, инфузии жидкости и вентиляции легких осуществляли обычным „ручным“ способом и тремя независимыми АСУ соответственно, сравнили с точки зрения качества анестезии и последующих когнитивных расстройств. Пациенты в „автоматической“ группе провели меньше времени с индексом $\mathrm{BIS}<40$ (слишком глубокая анестезия), реже имели выраженную гипервентиляцию и обнаружили более выгодный водный баланс, нежели больные группы „ручного“ управления. Наконец, они продемонстрировали достоверно меньшую выраженность послеоперационной когнитивной дисфункции, чем после традиционно управляемой анестезии! Учитывая авторитет госпиталя, где проводилась работа, и журнала, опубликовавшего ее результаты, будущее влияние этого пилотного исследования на умонастроения врачебного сообщества трудно переоценить.

Конечно, существуют и объективные трудности создания подобных систем. Во-первых, это проблемы адекватной интерпретации входящего физиологического сигнала. Сигнал для систем с обратной связью должен быть легко идентифицируем, динамичен, свободен от помех и артефактов, малозависим от влияния сторонних факторов. В этом плане даже простые частотные преобразования нативной ЭЭГ крайне несовершенны для контроля глубины анестезии, и только, например, биспектральный индекс (BIS), как наиболее приемлемый на сегодняшний день вариант обработки физиологического сигнала, может с определенной степенью достоверности служить для этой цели [66].

Во-вторых, это несовершенство контроллеров, а также необходимость мультипараметрического анализа с низкой вероятностью ошибки и высокой степенью надежности системы. Решение этой проблемы, по-видимому, лежит в постепенном отказе от использования ПИДалгоритмов. Возможно, более надежной альтернативой для управления процессами, которые плохо поддаются формальному математическому описанию, будут в ближайшем будущем алгоритмы на основе нечеткой логики, нейронные сети или алгоритмы с возможностью самообучения [70].

\section{6. Парадокс анализа и синтеза: интегральная оценка состояния организма}

Медицинский мониторинг следует за развитием медицины, двигаясь преимущественно по аналитическому пути: с первых лет учебы врача приучают к анализу состояния пациента „по органам и системам“. Но по мере углубления в детали отдельных функций (известно более 3000 параметров состояния органов и систем!) [71], мы все более упускаем из вида функциональное состояние организма (ФСО) как целого. В то же время практика часто требует интегральных, синтетических оценок состояния - больного, находящегося в отдаленном районе, раненного или пораженного при медицинской сортировке, летчика, которому сейчас предстоит посадка на авианосец, спортсменов при отборе на чемпионат и т.д. Физики и медики, физиологи и спортивные врачи неоднократно внедряли различные интегральные показатели, угрозометрические шкалы и функциональные тесты, претендующие на эту роль [72,73], однако по разным причинам ни один из них пока не нашел широкого применения в ежедневной практике.

Работа в этом направлении, однако, не только не остановилась, но привлекает все бо́льший интерес. Наряду с аналитическим поиском, ведущим „внутрь и вглубь“ организма, обозначился встречный поток исследований, восходящих на все более высокие системные уровни [74-76] и оперирующих понятиями функциональной системы, гомеостаза, адаптации. Работы H. Selye, П.К. Анохина, Р.М. Баевского признаны классикой, нет сомнений в роли интегрирующих систем - эндокринной, центральной и автономной нервной (АНС) и важности их изучения $[74,75,77]$.

Попытки разрешения этого парадокса посвящены разделы 4 и 5 настоящего обзора. 


\section{4. Анализ вариабельности ритма сердца}

Ни один из известных сегодня показателей не дает полного представления о том, насколько критично состояние пациента. Одним из первых подходов, обещавших решение подобных задач, явился анализ вариабельности ритма сердца (ВРС). Понимание того, что сердечнососудистая система является одним из самых динамичных, а потому чувствительных и надежных индикаторов практически всех происходящих в организме процессов, позволило выбрать ключевой параметр, характеризующий адаптационный потенциал и гомеостаз. Основоположником метода в СССР считается Р.М. Баевский (р. 1928), который в интересах космической медицины применительно к механизмам ритмогенеза сердца использовал надсистемный подход, говоря о ВРС, как интегральном показателе ФСО. В „штатном“ состоянии организма регуляция работает в режиме контроля, который характеризуется большим числом степеней свободы подчиненных систем. В процессах нормальной адаптации организма к воздействию стрессовых факторов ведущую роль играет симпатическое звено автономной нервной системы (АНС), которая интегрирует физиологические системы, выводя их на необходимый уровень функциональной мобилизации. При этом происходит централизация управления с уменьшением числа степеней свободы генератора ритма и снижением вариабельности ритма сердца (ВРС) [78].

Развитие этого подхода началось с временно́го анализа ВРС - статистического анализа данных с элементами вероятностного подхода [79]. Вычисляемые показатели (NN, AMo, Var, SDNN, RMSSD и др.) и интегральные индексы (Баевского, вегетативного равновесия, вегетативный показатель ритма и др.) достаточно обоснованно характеризуют состояние сердечно-сосудистой системы, наличие ваго- или симпатотонии, степень напряжения экстракардиальной регуляции ритма [79-84]. Более информативна обработка данных ВРС спектральными методами, оценивающими вклад в динамику ритма отдельных периодических составляющих. Математические преобразования (например, быстрое преобразование Фурье) позволяют представить кардиоинтервалограмму в виде интерференции правильных синусоид различной частоты и амплитуды. Затем рассчитывают спектральную мощность колебаний и определяют площади под кривыми определенных частотных диапазонов. Соотношение мощностей компонентов спектра характеризует сравнительный вклад симпатического и парасимпатического каналов в регуляцию ритма [78-84].

Разновидность спектрального анализа - вейвлетпреобразование, также выявляющее информацию, незаметную в частотно-временно́м представлении сигнала. Здесь роль синусоид, на которые разлагают сигнал, играют короткие колебания (англ. wavelets) [85]: нестационарный сигнал анализируют разложением по базисным функциям, полученным из некоего прототипа путем сжатий, растяжений и сдвигов. Функцию-прототип называют анализирующим (материнским) вейвлетом, выбор которого определяется видом информации, которую требуется получить из сигнала [86].

Неоднородность процесса формирования синусового ритма позволяют оценить методы корреляционного анализа: чем выраженнее различные влияния на процесс, тем слабее взаимосвязь между последующими и предыдущими значениями исследуемого динамического ряда. Автокорреляционная функция отражает динамику коэффициентов корреляции, получаемых при последовательном смещении анализируемого динамического ряда на одно и то же число по отношению к исходному ряду $[75,78]$. Чем менее однороден ряд (свидетельство нестабильности автономного контура управления), тем значительнее падение коэффициента корреляции уже после первого сдвига. Нестационарные ритмы, например, при мерцании предсердий, описывают корреляционной ритмограммой или скаттерограммой интервалов $\mathrm{R}-\mathrm{R}$ на плоскости в прямоугольных координатах: по оси абсцисс откладывают величину $\mathrm{R}-\mathrm{R}_{n}$, по оси ординат $\mathrm{R}-\mathrm{R}_{n+1}$. Облако точек (пятно Пуанкаре или Лоренца), сосредоточенное на биссектрисе координатного угла, свидетельствует об эффективном контроле ритма главным пейсмейкером, амодальные скаттерограммы с рассеянным облаком отражают отсутствие контроля второстепенных водителей ритма синусовым узлом [82,83].

Дальнейшее развитие методов исследования ВРС coздает возможность изучения нелинейной динамики ритма [87] как компонента сложной системы с большим количеством связей и многообразных влияний, характеризуемой динамическим хаосом (самоподдерживающимися стохастическими колебаниями) и фрактальностью (самоорганизующейся симметрией самоподобия). Симбиоз детерминированных и хаотических составляющих фрактальной структуры обнаруживается при анализе многих ритмов, отражающих физиологические показатели энергообмена и саморегуляции - электрических потенциалов сердца, мозга и желудочно-кишечного тракта, паттерна дыхания, тремора конечностей, колебаний потенциалов на поверхностях раздела ткань-жидкость идр. [88]. Другие признаки хаотических колебаний физиологических сигналов - сплошной спектр мощности с отрицательным показателем зависимости от частоты, быстро спадающая во времени автокорреляционная функция, положительный характеристический показатель Ляпунова [89].

Стохастическая иррегулярность таких сигналов в координатах „величина - скорость ее изменения“ проявляется в виде притягивающего множества фазовых траекторий (так называемого странного аттрактора [90]), который обладает дробной (фрактальной) размерностью, количественно отражающей неэвклидову зависимость между скоростями увеличения элементов фрактала и интервала масштабов, на котором они рассматриваются [91]. Для качественной оценки в фазовом пространстве этого притягивающего множества, органи- 


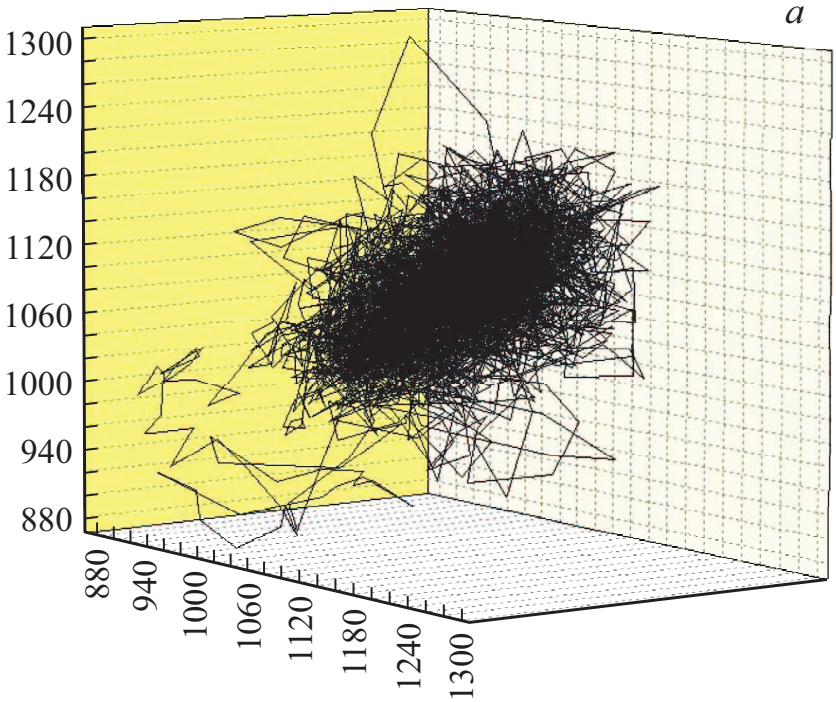

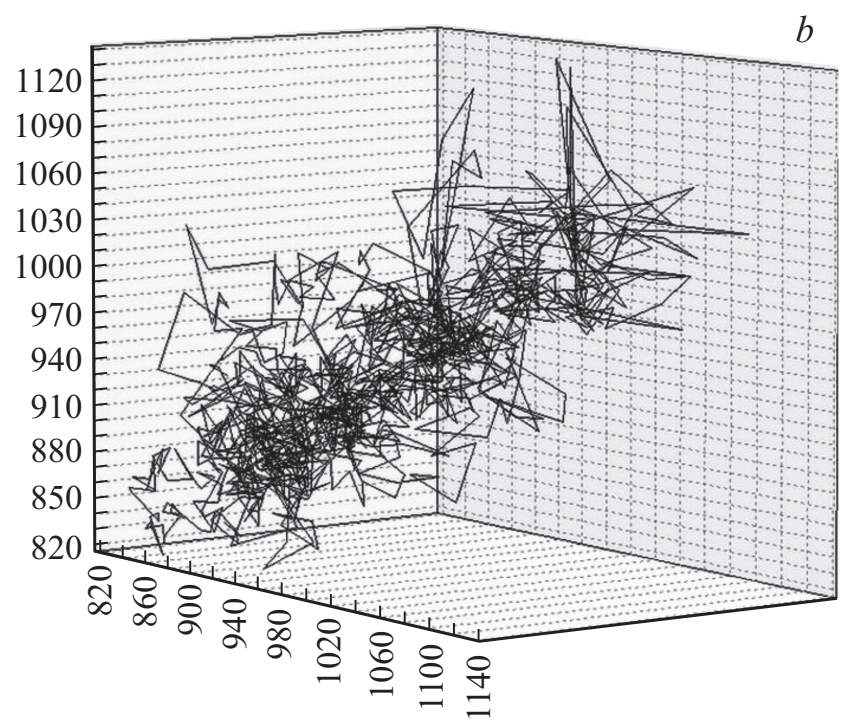

Рис. 4. Фазовый портрет ритма сердца: $a-$ здорового человека, $b-$ при патологии [93].

зуемого хаотическим поведением сложной динамической системы с характером детерминированного хаоса, используется визуальная картина аттрактора, которая определяет причину нерегулярности поведения нелинейных систем экспоненциальным быстрым разводом первоначально близких траекторий в ограниченной области фазового пространства [80]. Восстановленный из $\mathrm{R}$ - R-интервалограммы аттрактор в $\mathrm{N}$-мерном фазовом пространстве и будет отражать ФСО. Давая различные тестовые нагрузки, можно по динамике размерности аттрактора идентифицировать контур адаптации и оценивать его напряженность [80,92].

Анализ нелинейной динамики ритма показал, что состояние уравновешенного взаимодействия всех звеньев регуляции ритма (эйтонии) характеризуется фазовым портретом с преобладанием эллипсоподобных циклов волновой структуры ритма: частота сердечных сокращений (ЧСС) сначала постепенно увеличивается, а затем уменьшается. Странный аттрактор на фазовом портрете представлен „клубком ниток“, где размерность системы определена множеством факторов влияния на ФСО (рис. 4,a). Нарушение гармонии взаимодействия вегетативной и гуморальной регуляции ритма меняет геометрическую структуру фазового портрета, размерность аттрактора снижается (рис. 4, $b$ ) [80,93].

С применением нелинейного анализа исследования ВРС обрели „второе дыхание“. Фазовый портрет синусового ритма, отражающий нелинейную динамику совокупности внешних условий и внутренней регуляции сердца, воплощается в пространственном образе индивидуальной виртуальной паутины [94]. Форма, размах и пространственная ориентация фазового портрета синтезируют в себе и временно́й ряд, и пространственный объем вариабельности ритма. Возможно, именно это имел в виду Р.М. Баевский, говоря «о характеристике ВРС с общебиологической точки зрения, как за- кономерного проявления сущности ключевого понятия „жизнь““ $\gg[95]$.

\section{5. Применение физических и информационных методов для интегральной оценки ФСО}

Наиболее перспективные идеи в изучении состояния организма как целостной системы закономерно исходят из области физики. С развитием термодинамики и квантовой механики интересы исследователей сместились в направлении изучения стохастических и нелинейных процессов, описываемых вероятностно-статистическими моделями. Описание однозначной причинной связью идеализированных частных случаев поведения сложных систем ушло в историю вместе с эпохой детерминизма, отличавшего естествознание XVII-XVIIIвв. [96]. Большинство отраслей науки перестроило свои базовые теории на основе новой парадигмы [97], однако в медицине по-прежнему доминируют „эмпирические“ (точнее, архаичные) представления о детерминированном характере причинно-следственных связей в такой сложнейшей открытой системе, как живой организм. Несмотря на декларации персонализированного подхода, даже из современной идеологии рандомизированных клинических исследований и построенных на основе их результатов клинических рекомендаций почти полностью исключены как индивидуальные особенности пациента, так и взаимодействие повреждений нескольких систем организма. Этому объективно способствовало эпохальное открытие этиологии инфекционных и паразитарных заболеваний: каждое из них вызывается своим специфическим возбудителем, и причинно-следственная связь действительно представала предопределенной. Позднее осознали, что один контакт заболевает, а другой - нет, один и тот 
же вирус у одного пациента вызывает корь, у другого энцефалит, у третьего - опоясывающий лишай . . И все же идентификация возбудителя и этиотропное лечение остаются для медицины идеалом - отсюда попытки (подчас успешные!) поиска возбудителей опухолей, язвенной болезни и даже усталости.

Niels Bohr (1885-1962) подходил к проблеме с позиций принципа дополнительности, полагающего, подобно принципу неопределенности в квантовой механике, исследования живых объектов на молекулярном уровне и как целостных систем дополнительными по отношению друг к другу, т.е. несовместными. В „Теоретической биологии“ Э.С. Бауэра выдвигалась концепция особого физического состояния „живого вещества“ [98]. Эти взгляды отошли в историю по мере развития молекулярной биологии, приведшего к атомистическому толкованию наследственности и изменчивости [99], с одной стороны, и развития физической теории биосистем на основе идей синергетики [100], рассматривающей образование и самоорганизацию упорядоченных динамических структур в открытых системах, далеких от термодинамического равновесия, с другой. В середине XX в. Erwin Schrödinger (1887-1961) в книге „Что такое жизнь?“ ввел трактовку организма как открытой системы, обменивающейся с окружающей средой веществом и энергией, неравновесное состояние которой поддерживается оттоком энтропии в среду [101].

Понимание этого баланса создает возможность донозологической диагностики на основе оценки расхождения результатов прямой и непрямой калориметрии. Логика отталкивается от второго начала термодинамики, устанавливающего направление протекания самоорганизующихся процессов преобразования энергии, а также сопутствующего изменения энтропии в качестве меры ее диссипации и критерия термодинамической эволюции организма, и теоремы И.Р. Пригожина о минимальном производстве энтропии для стационарных состояний $[102,103]$ : условием стационарного состояния является равенство продукции энтропии, произведенной организмом, потоку энтропии за его пределы [102]. В отличие от хронической адаптации, носящей преимущественно структурный, морфологический характер, острая адаптация энергозависима, и ее интенсивность можно оценить через баланс энергии, а также сопутствующие изменения энтропии в качестве меры ее диссипации и критерия термодинамической эволюции организма. Отсюда - возможность диагностировать изменения ФСО на раннем этапе перестройки энергетического обмена и управления гомеостазом [104]. Любой необратимый процесс, сопровождающийся увеличением образования теплоты диссипации и соответственно продукцией энтропии, будет сопровождаться расхождением показаний прямого калориметра с данными расчета непрямой калориметрии в пользу первого. Справедливо и обратное: все, что связано с усилением процессов синтеза и повышением структурности живой материи, ведет к уменьшению производства энтропии и преобладанию расчетной величины [75]. Увы, громоздкие прямые калориметры для всего тела не позволяют реализовать этот метод мониторинга не только в операционной, но даже и в отделении реанимации.

Альтернативный подход к интегральной оценке ФСО и прогнозированию угроз жизнеспособности организма основан на энтропийной оценке интенсивности регуляторных воздействий по информационной насыщенности процессов управления гомеостазом, отражаемых в вариабельности его физиологических ритмов. Базой этого подхода служит современная концепция синергетического понимания самоорганизации взаимосвязанного функционирования всех органов живого организма как неравновесной открытой системы и вероятностностатистическая трактовка понятия энтропии, предложенная Ludwig Bolzman (1877) [105]. Энтропия как мера неупорядоченности находится в прямой зависимости от термодинамической вероятности состояния системы. Чем бо́льшим числом микросостояний может быть реализовано это макросостояние (т.е. чем ниже упорядоченность системы), тем выше вероятность такого состояния, т.е. энтропия. Позднее с позиций теории информации К. Шеннон и Н. Винер экстраполировали понятие энтропии за пределы термодинамических систем [106], показав взаимосвязь понятий информационной энтропии (или количества информации о системе) и термодинамической энтропии Больцмана. Это отождествление позволяет с достаточно обоснованной аналогией закономерностей, известных для термодинамической энтропии, оценивать по информационной энтропии состояние организма в плане упорядоченности или неупорядоченности функционирования его составных частей [107,108]. Оценка информационной энтропии технически возможна значительно более простыми способами: входными данными при этом может быть дискретная временна́я последовательность биомедицинских сигналов любой природы - электрокардиограммы, электроэнцефалограммы, фотоплетизмограммы, ритма дыхания или величин ударного объема крови и др., гистограмма которых отражает частотную вероятность текущего распределения характеристик ФСО [109].

Одним из воплощений идеи стал метод мониторинга и прогнозирования общей устойчивости ФСО по фрактальному анализу генерации информационной энтропии физиологических ритмов $[75,110]$. Как уже отмечалось, оценка состояния сложнейшей динамической системы, подверженной самым разнообразным влияниям, требует применения нелинейных методов исследования; для наблюдения эволюции динамической системы во времени необходимо построение и анализ ее фазового портрета. Объединив теоретические предпосылки методов нелинейного анализа ВРС и оценки продукции физической энтропии в процессах обмена энергии и вещества организма по информационной насыщенности регуляторных воздействий на гемеостаз, можно мониторировать ФСО на основе фазового портрета энтропийного аттрактора. Для количественной оценки его характеристик авторы 

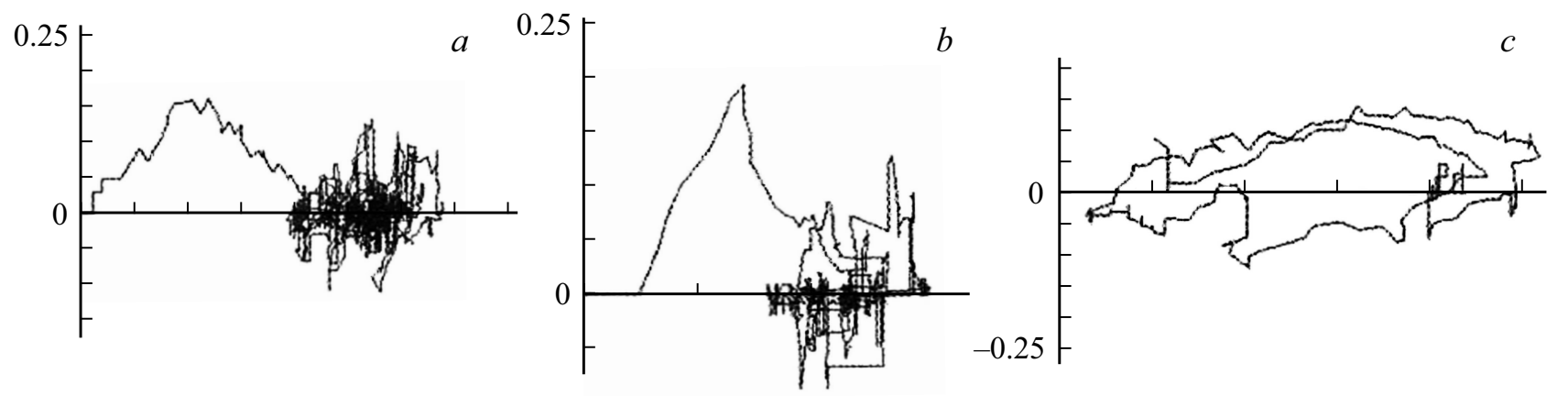

Рис. 5. „Энтропийное состояние“: $a$ - мальчик 14 лет, $b-$ женщина 79 лет, $c-$ мужчина 57 лет с острым нарушением мозгового кровообращения за 3 min до смерти [75].
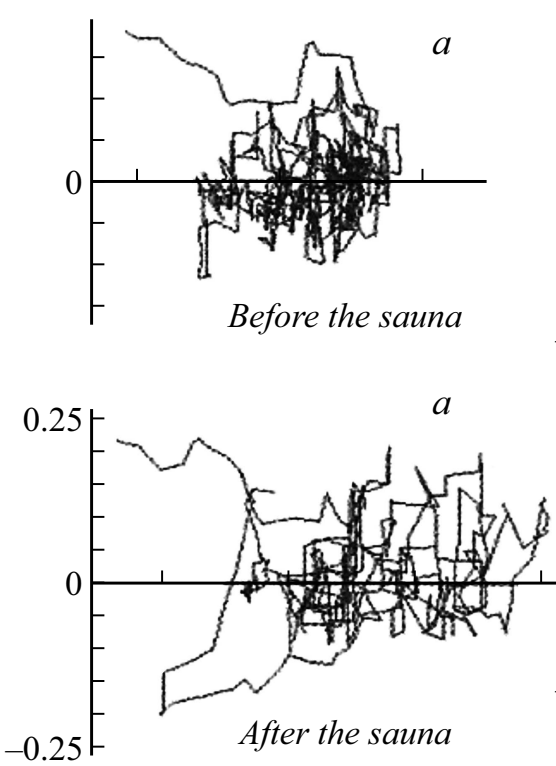

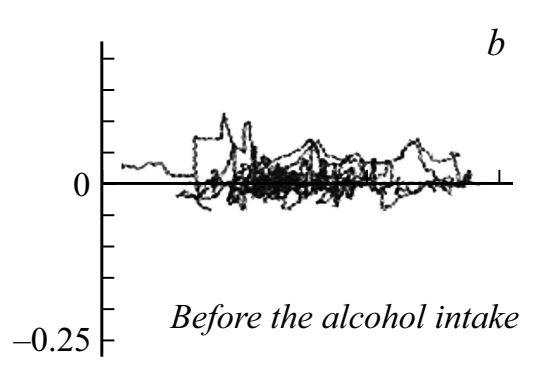

b

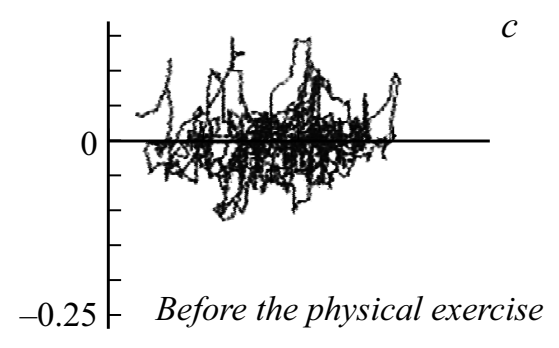

b

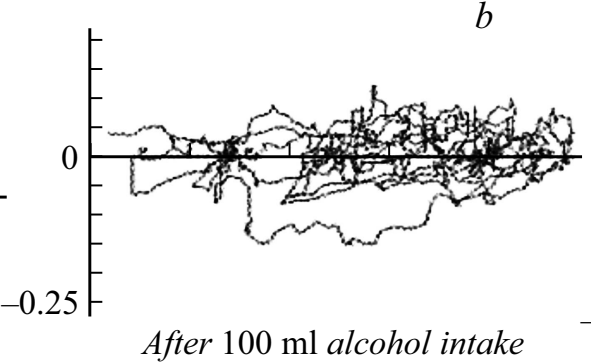

Рис. 6. „Энтропийное состояние“ здоровых людей: $a-$ изменение после сауны, $b-$ влияние алкоголя, $c-$ эффект физической нагрузки [75].

использовали вероятностные (фрактальные) размерности, общим выражением которых является размерность Реньи [111], переходящая в частных случаях в известные выражения Колмогорова-Синая-Хаусдорфа-Шеннона. На этой основе с учетом известной неопределенности понятий „норма“ и „патология“, а также приоритета упреждающей оценки развития критических состояний, выявление и прогнозная оценка напряженности угроз ведется по динамическому тренду фрактальной размерности аттрактора энтропии, плотность генерации которой в системе взаимосвязанных органов интегрально отражает эволюцию состояния организма в целом. Работоспособность запатентованного способа мониторинга ФСО человека в реальном масштабе времени [112] доказана в исследованиях, основанных на записях ЭКГ как клинического, так и высокого разрешения с большой частотой дискретизации, доступной современным кардиографам и холтеровским мониторам. Для математической обработки создан программный комплекс, протестированный на известных моделях систем дина- мического хаоса (Ресслера и Лоренца) и нелинейных отображений (Хенона, Икеды, Лози), апробированный в доклинических и клинических исследованиях, в том числе с использованием баз данных европейского медицинского сервера PhysioNet [113]. Источником диагностических данных в вариациях ЭКГ являются ,аттракторные“ отображения одновременно величины и скорости изменения генерируемой при этом информационной энтропии, реконструкция которых во временных рядах стандартных измерений осуществляется методом задержки по теореме Такенса [114].

Продемонстрированы различия между людьми разного пола и возраста, заключающиеся в визуально различимой „Плотности“ фазовых траекторий в аттракторе информационной энтропии ЭКГ: от „тугонамотанного клубка“ у здорового молодого человека (рис. 5, $a$ ) и его „разрыхления“ при заболеваниях и старении (рис. 5,b), при тепловой (рис. 6, $a$ ), алкогольной (рис. $6, b)$ и физической нагрузке (рис. $6, c$ ), вплоть до вырождения в отдельные „петли“ у умирающего пациента (рис. 5, c). Ана- 
лиз трендов корреляционной размерности энтропийных аттракторов приводит к следующим выводам [75,115]:

1. Для здорового организма характерно колебание нецелочисленной корреляционной размерности в пределах от 1 до 3 с ее уменьшением в ночные часы.

2. Возможны непродолжительные эпизоды снижения корреляционной размерности в диапазон от 0 до 1 в ночные часы, как у здоровых, так и у больных людей, что, по всей видимости, связано с изменениями ритма сердца в процессе сна.

3. Жизнеопасными изменениями корреляционной размерности, требующими интенсивного наблюдения и лечения, являются, во-первых, ее устойчивое приближение к целочисленному значению и его длительное сохранение; во-вторых, резкое или длительное снижение корреляционной размерности в интервал $0 \ldots 1$.

Подчеркнем в заключение, что „синтетический“ мониторинг ФСО призван не заменить, а дополнить традиционные „аналитические“ виды мониторинга, позволяющие находить поврежденное звено: они решают разные, но в равной степени важные задачи.

\section{Заключение}

Медицинский мониторинг - протяженное во времени наблюдение за каким-либо физиологическим параметром, процессом или функцией в реальном времени, предоставляющее медицинскому персоналу информацию, способную, при условии правильной и единообразной ее интерпретации, обеспечить своевременное принятие тактических решений и мер, положительно влияющих на исходы лечения. К наиболее значимым проблемам мониторинга, способным влиять на его клиническую эффективность, относят: адекватность интерпретации получаемых данных медицинским персоналом; помехи и артефакты сигнала, нарастающие по мере отягощения состояния пациента и создающие противоречие между точностью и временно́й фокусировкой отсчетов; технологическую дисциплину работы с мониторами; информационную перегрузку оператора. Оптимальный медицинский мониторинг всегда предполагает рациональное сочетание объектов, методов и технологий; чрезмерная фокусировка внимания на каком-либо одном объекте, методе или технологии мониторинга неизбежно ведет к искаженному восприятию ситуации, а нередко и к прямому вреду для пациента. Пристального внимания врачей и инженеров требуют две комплексные проблемы - создание систем автоматического управления физиологическими функциями на основе замкнутой петли обратной связи и мониторинг интегральной оценки физиологического состояния организма человека.

\section{Конфликт интересов}

Авторы заявляют, что у них нет конфликта интересов.

\section{Список литературы}

[1] Лебединский К.М. Мониторинг как метод в анестезиологии. В кн.: Кровообращение и анестезия. 2-е изд. СПб.: Человек, 2015. С. 104-127.

[2] Merriam-Webster's Collegiate Dictionary. Springfield: Merriam-Webster, 1993. $1561 \mathrm{p}$.

[3] Новые слова и значения. Словарь-справочник под ред. Н.З. Котеловой и Ю.С. Сорокина. М.: Советская энциклопедия, 1973. 543 c.

[4] The American Heritage Dictionary of the English Language. Ed. by W. Morris. NY.: American Heritage Publishing Co., 1969. $1550 \mathrm{p}$.

[5] Дворецкий И.Х. Латинско-русский словарь. 2-е изд. М.: Русский язык, 1976. 1096 с.

[6] Eichhorn J.H., Cooper J.B., Cullen D.J. et al. // JAMA. 1986 Aug 22-29. Vol. 256. N 8. P. 1017-1020.

[7] Siegenthalers Differenzialdiagnose Innerer Krankheiten vom Symptom zur Diagnose. Hrsg von E. Battegay. 20 Aufl. Stuttgart-New York: Georg Thieme, 2013. 1167 p.

[8] Barker S.J. Pulse Oximetry. In: Ehrenwerth J., Eisenkraft J.B., Berry J.M. Anesthesia Equipment: Principles and Applications. $2^{\text {nd }}$ ed. Elsevier Saunders, 2013. P. 257-272.

[9] Severinghaus J.W., Astrup P.B. // J. Clin. Monitor and Comp. 1986. Vol. 2. N 4. P. 270-288. DOI: $10.1007 /$ BF02851177

[10] Kpenc E.M. Оксигемометрия. Техника, применение в физиологии и медицине. Л.: Медгиз, 1959. 224 с.

[11] Steven R.C., Slater H.M., Johnson A.L. // Anesthesiology. 1951. Vol. 12. P. 548.

[12] Котомина Г.Л., Доманская И.А., Лебединский К.М. Ваневский В.Л. СПб.: Издат. дом СПбМАПО, 2006. 56 с.

[13] Barker S., Curry J., Redford D., Morgan S. // Anesthesiology. 2006. Vol. 105. P. 892-897.

[14] Jurban A. // Crit. Care. 2015. Vol. 19. P. 272. DOI 10.1186/s13054-015-0984-8

[15] Лебединский К.М., Мазурок В.А., Матус К.М. // Медицинская техника. 2010. Vol. 4. Vol. 25-30.

[16] Cooper J.B., Newbower R.S., Long C.D., McPeek B. // Anesthesiology. 1978. Vol. 49. P. 399-406.

[17] Webb R.K., Currie M., Morgan C.A. et al. // Anaesth. Int. Care. 1993. Vol. 21. N 5. P. 520-528.

[18] Jha A.K., Kuperman G.J., Teich J.M. et al. // J. Am. Med. Inform. Assoc. 1998. Vol. 5. P. 305-314.

[19] Ли Э.Б., Маркус Л. Основы теории оптимального управления. М.: Наука, 1972. 576 с.

[20] Поповских П.Я., Кукушкин А.В. Подготовка войскового разведчика. М.: Воениздат, 1991. $336 \mathrm{c.}$

[21] Hall J.B. // In: Functional Hemodynamic Monitoring / Eds. M.R. Pinsky, D. Payen. - Springer, 2005. P. 233-240.

[22] Satkurunath G., Rhodes A., Cecconi M. // In: Patient Safety and Quality of Care in Intensive Care Medicine. Eds. J.-D. Chiche, R. Moreno, C. Putensen, A. Rhodes (ESICM). Berlin: Medizinisch Wissenschaftliche Verlagsgesellschaft. 2009. P. 433-440.

[23] Расследование преступлений, совершенных медицинскими работниками по неосторожности (ятрогенных преступлений). М.: Юнити-Дана, 2016. 159 с.

[24] Гнездицкий В.В. Вызванные потенциалы мозга в клинической практике. М.: МЕДпресс-информ, 2003. 264 с. 
[25] Tsurukiri J., Nagata K., Hoshiai A. et al. // Scandinav. J. Trauma, Resuscitation and Emergency Medicine. 2015. Vol. 23. P. 80. DOI 10.1186/s13049-015-0161-8

[26] Kochs E., Bischoff P. // Der Anaesthesist. 1994. Nov. Vol. 43. Suppl 2. P. S8-14.

[27] Marik P.E. Handbook of Evidence-Based Critical Care. Springer, 2001. $535 \mathrm{p}$.

[28] Eidelman L.A., Pizov R., Sprung C.L. // Curr. Op. in Crit. Care. 1996. June: P. 183-186.

[29] Межсгосударственный авиационный комитет. Окончательный отчет по расследованию авиационного происшествия. https://mak-iac.org/upload/iblock/807/finalreport_rus.pdf

[30] Чапкис Д.Т. Гибель „Адмирала Нахимова“. Р.-на-Д.: Проф-Пресс, 1995. 606 с.

[31] Hewitt R.M. The Physician-Writer's Book. London: W.B. Sounders Co., 1957. 415 p.

[32] Коллиер Джс., Хьюитт Джс. Введение в ядерную энергетику / Пер. с англ. под ред. В.В. Хромова. М.: Энергоатомиздат, 1989. $256 \mathrm{c}$.

[33] Котик М.A. Курс инженерной психологии. Таллин: Валгус, 1978. 364 с.

[34] Электронный ресурс режим доступа: https:/www.hamil-ton-medical.com/ru_RU/E-Learning-andEducation/College.html

[35] Block F.E.Jr., Yablok D.O., McDonald J.S. // Int. J. Clin. Monit. Comput. 1995. Feb. Vol. 12. N 1. P. 21-4.

[36] Schlosser P.D., Grundgeiger T., Sanderson P.M., Happel O. // Int. J. of Clin. Monit. Comput. 2019. Dec. Vol. 33. N 6. P. 1119-1127. DOI: $10.1007 / \mathrm{s} 10877-019-00265-4$

[37] Drake-Brockman T.F., Datta A., von UngernSternberg B.S. // Paediatr Anaesth. 2016. Vol. 26. N 5. P. 539-546. DOI: 10.1111/pan.12879

[38] Bellomo R., Uchino S. // Curr. Op. Crit. Care. 2003. Vol. 9. P. 225-229.

[39] Moller J.T., Johannessen N.W., Espersen K. et al. // Anesthesiology. 1993. Vol. 78. N 3. P. 445-453.

[40] McConachie I. (Ed.) Anaesthesia for the High Risk Patients. London, San Francisco: Greenwich Medical Media Limited, 2002. $265 \mathrm{p}$.

[41] Лебединский К.М., Курапеев И.С. Катетеризация легочной артерии. В кн.: Кровообращение и анестезия. 2-е изд. СПб.: Человек, 2015. С. 294-339.

[42] Cowley G., Hager M. // Newsweek. 1996. September. Vol. 30. P. 71.

[43] Gore J.H., Goldberg R.J., Spodnick D.H. et al. // Chest. 1987. Vol. 92. P. 721-727.

[44] Connors A.F.Jr., Speroff T., Dawson N.V. et al. // JAMA. 1996. Vol. 276. P. 889-897.

[45] Dalen J.E., Bone R.C. // JAMA. 1996. Vol. 276. P. 916-918.

[46] Shoemaker W.C. // Сб. тез. VI Всеросс. съезда анест. и реанимат. М., 1998. C. 44-45.

[47] Ramsey S.D., Saint S., Sullivan S.D. et al. // Cardioihor Vasc. Anesth. 2000. Vol. 14. P. 113-118.

[48] Resano F.G., Kapetanakis E., Hill P.C. et al. // Cardiothor Vasc. Anesth. 2006. Vol. 20. P. 300-306.

[49] Sandham J.D., Hull R.D., Brant R.E. et al. // New Engl. J. Med. 2003. Vol. 348. P. 5-14.

[50] Polanczyk C.A., Rohde L.E., Goldman E. et al. // JAMA. 2001. Vol. 286. P. 309-314.
[51] Harvey S., Harrison D.A., Singer M. et al. // Lancet. 2005. Vol. 366. P. 472-477.

[52] Rhodes A., Cusack R.J., Newman P.J. et al. // Int. Care. Med. 2002. Vol. 28. P. 256-264.

[53] Sakr Y., Vincent J.-L., Reinhart K. et al. // Chest. 2005. Vol. 128. P. 3098-3108.

[54] Binanay C., Califf R.M., Hasselblad V. et al. // JAMA. 2005. Vol. 294. P. 1625-1633.

[55] Yu D.T., Platt R., Lanken P.N. et al. // Crit. Care. Med. 2003. Vol. 31. P. 2734-2741.

[56] Richard C., Warszawski J., Anguel N. et al. // JAMA. 2003. Vol. 290. P. 2713-2720.

[57] Pulmonary artery catheter versus... // New Engl. J. Med. 2006. Vol. 354. P. 2213-2224.

[58] Comparison of two fluid-management... // New Engl. J. Med. 2006. Vol. 354. P. 2201-2212.

[59] Leibowitz A.B., Oropello J.M. // Sem. Cardiothor Vasc. Anesth. 2007. Vol. 11. P. 162-176.

[60] Pinsky M.R., Vincent J.-L. // Crit. Care. Med. 2005. Vol. 33. P. $1119-1122$.

[61] Angus D.C., Linde-Zwirble W.T., Lidicker J. et al. // Crit. Care. Med. 2001. Vol. 29. P. 1303-1310.

[62] Cecconi M., De Backer D., Antonelli M. et al. // Int. Care. Med. 2014. Vol. 40. P. 1795-1815. DOI 10.1007/s00134-014-3525-z

[63] Канд. дис. Магилевец, В.М. Общая анестезия с регуляцией по обратной связи во время операций с искусственным кровообращением: ДиМ., 2006. 209 с.

[64] Гусев А.Н. Системы автоматического управления самолетом. Самара: СГАКУ, 2004. 138 с.

[65] Myles P.S., Leslie K., McNeil J. et al. // Lancet. 2004. Vol. 363. P. 1757-63.

[66] Hajat Z., Ahmad N., Andrzejowsky J. // Anaesthesia. 2017. Vol. 72. (Suppl. 1). P. 38-47. DOI: 10.1111/anae.13739

[67] Neckebroek M., Ionescu C.M., van Amsterdam K. et al. // J. of Clin. Monitor Comput. 2018. Vol. 33. N 4. P. 675-686. DOI.org/10.1007/s10877-018-0208-2

[68] Atchabahian A.M., Hemmerling T. // Anesth. Pain. Med. 2014. Vol. 4. N 1. P. e16468. DOI: 10.5812/aapm.16468

[69] Joosten A., Rinehart J., Bardaji A. et al. // Anesthesiology. 2020. Vol. 132. P. 253-266.

DOI: $10.1097 /$ ALN.0000000000003014

[70] Dumont G.A., Ansermino J.M. // Anesth. Analg. 2013. Vol. 117. N 5. P. $1130-1138$. DOI: 10.1213/ANE.0b013e318297368

[71] Человек. Медико-биологические данные. М.: Медицина, 1977. $496 \mathrm{c}$.

[72] Войнов В.Б., Воронова Н.В., Золотухин В.В. Методы оценки состояния систем кислородообеспечения организма человека. Р.-на-Д.: УНИИ валеологии РГУ, 2002.

[73] Цыбулькин Э.К., Мешалкин Л.Д. // Компьютерные технологии в медицине. 1997. Vol. 2. Р. 49.

[74] Алдонин Г.М., Болотова Н.П., Тачеев А.Н., Желудько С.П. Дистанционный мониторинг функционального состояния человека // Сб. науч. тр. Всерос. науч.-техн. конф. „Современные проблемы радиоэлектроники“. М.: Радио и связь, 2010. С. 48.

[75] Носырев С.П., Коваленко А.Н. Основания анестезиологии и реаниматологии. М.: Ключ-С, 2014. 216 с.

[76] Chen C., Jin Y., Lo I.L. et al. // Int. J. Biol. Sci. 2017. Vol. 13. N 10. P. $1320-1328$. DOI: $10.7150 /$ ijbs. 19462 
[77] Mulkey S.B., Kota S., Swisher C.B. et al. // Early. Hum. Dev. 2018. Vol. 123. P. 11-16. DOI: 10.1016/j.earlhumdev.2018.07.003

[78] Баевский Р.М., Кириллов О.И., Клецкин С.З. Математический анализ изменений сердечного ритма при стрессе. М.: Наука, 1984. 221 с.

[79] Парин В.В., Баевский Р.М., Волков Ю.Н., Газенко О.Г. Космическая кардиология. Л.: Медицина, 1967. 206 с.

[80] Методические рекомендации по анализу вариабельности сердечного ритма у спортсменов в видах спорта на выносливость с применением математических методов. http://csp-athletics.ru/metodicheskie-rekomendatsii-po-kontro-lyu-sostoyaniya.html

[81] Task Force of the European Society of Cardiology and the North American Society of Pacing and Electrophysiology. // Circulation. 1996. Vol. 93. N 5. P. 1043-1065.

[82] Голухова Е.3., Алиева А.М., Какучая Т.Т. и др. // Креативная кардиология. 2009. Т. 1. С. 76-82.

[83] Ильина С.С., Чернеев А.С., Ефимова И.П., Уманская H.E., Запара B.B. // Вестник ОГУ. 2005. Т. 5. С. 115120.

[84] Хмельницкий И.В., Горбачев В.И., Горбачева С.М. // Вестник анестезиологии и реаниматологии. 2016. Т. 1. C. $53-58$.

[85] Дьяконов В.П. Вейвлеты. От теории к практике. М.: СОЛОН-ПРЕСС, 2008. 400 c.

[86] Куклин С.Г., Михалевич И.М., Рожкова Н.Ю. и др. Новое о колебательных преобразованиях в сердечном ритме (непрерывный вейвлет-анализ). В кн.: Атлас временных вариаций природных, антропогенных и социальных процессов. М.: Янус-К, 2013. С. 682-687.

[87] Cepeda F.X., Lapointe M., Tan C.O., Andrew T.J. // Auton. Neurosci. 2018. Vol. 213. P. 1-7. DOI: org/10.1016/j.autneu.2018.04.007

[88] Урицкий В.М., Музалевская Н.И. // Биомедицинская информатика и эниология. Сб. трудов. СПб.: Ольга, 1995. C. $84-129$.

[89] Анищенко В.С., Астахов В.В., Вадивасова Т.Е. и др. // Прикладная нелинейная динамика. 2003. Т. 3. № 11 . C. $190-194$.

[90] Колмогоров А.Н., Новиков С.П. Странные аттракторы. М.: Мир, 1981. 253 c.

[91] Mandelbrot B.B. The fractal geometry of nature. Vol. 1. NY: WH Freeman, 1982.

[92] Муха Ю.П., Бугров А.В. // Бюллетень Волгоградского НЦ РАМН. 2008. Т. 3. С. 50-51.

[93] Ардашев А.В., Лоскутов А.Ю. Практические аспекты современных методов анализа вариабельности сердечного ритма. М.: МЕДПРАКТИКА-М, 2011. 128 с.

[94] Андреев И.Л., Назарова Л.Н. // Пространство и время. 2015. T. 1-2 (19-20). С. 414-421.

[95] Баевский Р.М. // Клиническая информатика и телемедицина. 2004. Т. 1. С. 54-64.

[96] Felice D., Cafaro C., Mancini S. // Chaos. 2018. Vol. 28. N 3. P. 032101 . DOI: $10.1063 / 1.5018926$

[97] Пригожсин И., Стенгерс И. Порядок из хаоса: Новый диалог человека с природой: Пер. с англ. М.: Прогресс, 1986. $432 \mathrm{c}$.

[98] Бауэр Э.С. Теоретическая биология. М.-Л.: Изд-во ВИЭМ, 1935. $206 \mathrm{c}$.

[99] Волькенштейн М.В. Биофизика. М.: Наука, 1988. 592 с.
[100] Хакен Г. Синергетика. Иерархии неустойчивостей в самоорганизующихся системах и устройствах. / Пер. с англ. М.: Мир, 1985. 423 с.

[101] Шредингер Э. Что такое жизнь? / Пер. с англ. М.: АСТ, 2018. 288 c.

[102] Glansdorff P., Prigogine I. // Science. 1972. Vol. 176. N 4042. P. $1410-1420$.

[103] Зотин A.B. Термодинамическая основа реакций организмов на внешние и внутренние факторы. М.: Наука, 1988. $272 \mathrm{c}$.

[104] Лебединский К.М. Тенденции развития современной анестезиологии. В кн.: Кровообращение и анестезия. 2е изд. СПб.: Человек, 2015. С. 950-979.

[105] Перез Э.А. Вселенная погибнет от холода. Больцман. Термодинамика и энтропия. М.: Де Агостини, 2015. 160 c.

[106] Шеннон К. Работы по теории информации и кибернетике. / Пер. с англ. М.: ИЛ, 1963. 830 с.

[107] Zhang X.D. // Adv. Exp. Med. Biol. 2017. Vol. 1028. P. 3953. DOI: $10.1007 / 978-981-10-6041-0 \_3$

[108] Porta A., De Maria B., Bari V., Marchi A., Faes L. // IEEE Trans. Biomed. Eng. 2017. Vol. 64. N 6. P. 1287-96. DOI: 10.1109/TBME.2016

[109] Chen C., Jin Y., Lo I.L., Zhao H., Sun B., Zhao Q. et al. // Int. J. Biol. Sci. 2017. Vol. 13. N 10. P. 1320 DOI: $10.7150 /$ ijbs. 19462

[110] Антонов В.И., Загайнов А.И., Коваленко А.Н. // Научнотехнические ведомости СПбГПУ. 2009. Т. 6. С. 111-119.

[111] Rényi A. Probability Theory. Amsterdam: North-Holland, 1970. $670 \mathrm{p}$

[112] Носырев С.П., Григорьев В.А., Коваленко А.Н. Патент РФ № 2226067.

[113] PhysioNet-PhysioBank. https://www.physionet.org/physiobank/

[114] Takens F. // In: D.A. Rand, L.-S. Young. Dynamical Systems and Turbulence, Lecture Notes in Mathematics. Vol. 898. Springer-Verlag, 1981. P. 366-381.

[115] Данилевич Я.Б., Коваленко А.Н., Носырев С.П. // ДАН. 2009. T. 429. № 1. С. 135-138. 